\title{
Friction Analyses of Dimple-Structured Surface
}

\author{
Rodrigo Lima Stoeterau ${ }^{1}$, Andreas Janssen ${ }^{2}$ and Guilherme Mallmann ${ }^{2}$ \\ 1. Deptartment of Mechatronic Engineering and Mechanical Systems, Lab. of Surface Phenomenon, University of São Paulo, São \\ Paulo 05508-970, Brazil
}

2. Fraunhoffer Institute for Production Technology, Aachen 52074, Germany

\begin{abstract}
This paper proposes an investigation of the effects of laser engineering surface with dimple operating under lubrication. Dimples with semi-spherical geometry, with $100 \mu \mathrm{m}$ in diameter and $25 \mu \mathrm{m}$ in depth, were Laser-machined on the surfaces of high speed steel AISI H13 discs, with three different distribution densities applied over the surface. Pin-on-disc experiments were performed by using counter bodies made with AISI 440C and Tungsten carbide ISO K20 pins. The experiments provided data information on the influence of dimple distribution on the coefficient of friction. Numerical simulations were performed to understand the influence of the pin and disc surface roughness on the contact problem. The results suggest that the design of dimple-structured surfaces rely on nine main parameters: material contact pair and its respective hardness, Young Modulus, the roughness of the surfaces, the dimple design, the dimple distribution, the load applied, the velocity and the type of lubricant. A better performance can be obtained from a compromise solution over these parameters, and the dimple concentration has a dominance over the other parameters. The best results were obtained with a lower concentration of dimples, under higher speed and load. Numerical simulations can also be used as a design tool, supporting decisions regarding shape and distribution of the dimples and material selections for the contact pair.
\end{abstract}

Key words: Structured surface, dimples, numeric simulation.

\section{Introduction}

Reduction in energy consumption and improvement of wear resistance are key problems for most engineering systems with relative motion parts. This led to the development of tribological solutions based on engineered surfaces with dimples working under lubricated regime. Currently, this is a wide-open field of research, with many technological applications. The tribological system operating under lubricated dimpled surface has been investigated and some publications regarding the understating of the occurring phenomena are already known [1, 3-13].

The idea of structuring and texturizing surfaces to improve their tribological performance is not new. The use of temper process to alter the hardness of sliding surfaces to reduce the coefficient of friction, and to improve the wear resistance has long been in use. In the same manner, the scraping process in machine tools

Corresponding author: Rodrigo Lima Stoeterau, Academic title, degree, research fields: linear guides, flat metrological planes, and other mechanical systems with sliding guides has been in use since the beginning of the XX century, or earlier.

In 1966, Hamilton et al. [1] were one of the first to evaluate the effects of a texturized surface with micro-asperities produced by etching on a lubricated contact and suggested that the micro-cavities act as the micro-hydrodynamic bearing. In 1970, Moore [2] emphasized the need of scraping reference surfaces to improve the bearing capacity and to improve the sliding performance in a more systematic manner. More recently, the use of coatings for friction reduction and for surface texturing and structuring became more relevance in industry.

The reasons to use dimple-structured surfaces can be listed as:

- Surface quality and texture are important tribological factors to provide durable operation of components with relative motion;

- Usually smoother surfaces with no structural defects can reduce run-in time and can retard the rate of 
wear and surface degradation processes (i.e.: contact fatigue and delamination);

- Smooth surfaces are very effective in reducing friction under boundary lubrication regimes and can promote hydrodynamic lubrication.

Recent methods to improve the tribological performance of materials focus on producing geometrically defined structures or micro textures in a certain pattern and distribution on the surface. These micro textures, called dimples, can be manufactured in several shapes and distribution patterns; each produces a different tribological behavior on the contact. Micro textures can be produced by conventional micromachining, lithography, Laser machining, and others [1, 9-11].

The addition of geometrically structured dimples on surfaces with relative motion, working under lubricated conductions, brings an additional hydrodynamic lift force, reducing the friction force and the contact pressure on the asperities. Also, these microstructures can act as a lubricant reservoir in contact, acting when the lubrication regime is boundary or mixed. When we consider dry contacts, however, these dimples can act as a trap for debris, reducing the three-body contact problem. This paper aims at studying the contact interactions of bodies with lubrication and investigating how the presence of textures in certain patterns affects friction forces.

\section{Surface Dimple Structures Design}

Dimples are structure features with different sizes, shapes, depths and distribution patterns on surfaces with minimal roughness in order to provide means for controlling the friction and wear on components with relative motion. In order to investigate the effects of the structured surface operating under lubricated conditions, dimples with semi-spherical geometry were designed with $100 \mu \mathrm{m}$ in diameter and $25 \mu \mathrm{m}$ in depth, Fig. 1.

The design of dimple-structured surfaces must consider information regarding the Apparent Support

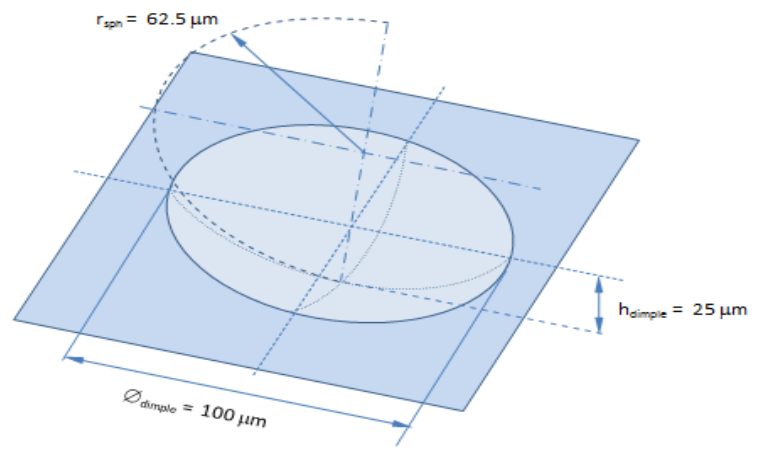

Fig. 1 Single dimple geometry.

Table 1 Relation between $\mathrm{D}_{\text {dimple, }}, \mathrm{Ap}_{\mathrm{sa}}$, and $\mathrm{D}_{\mathrm{AD}}$.

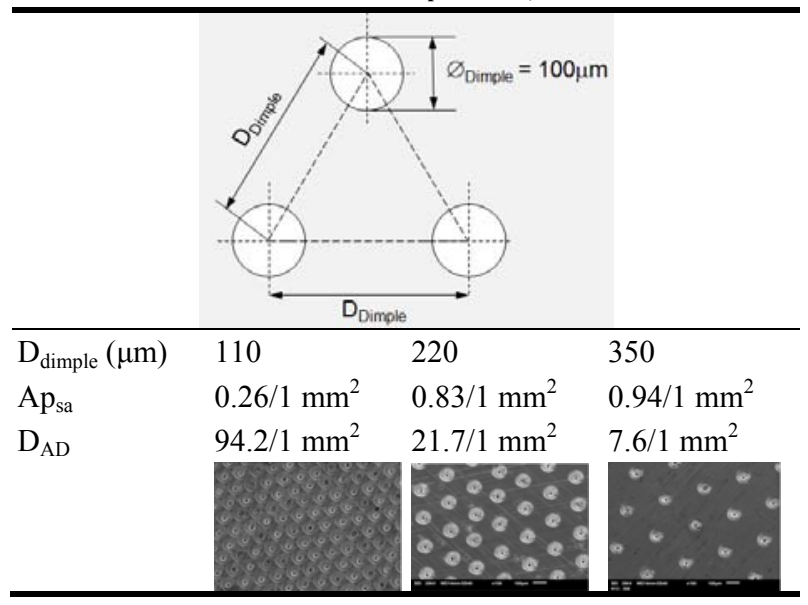

Area $\left(A p_{\mathrm{sa}}\right)$ and the Dimple Area Density $\left(\mathrm{D}_{\mathrm{AD}}\right)$. The Apparent Support Area $\left(\mathrm{Ap}_{\mathrm{sa}}\right)$ index expresses the area resulting from the subtraction of the dimples area from a circular area of $1 \mathrm{~mm}^{2}$. The Dimple Area Density $\left(D_{A D}\right)$ index represents the number of dimples set on a $1 \mathrm{~mm}^{2}$ area. Both indexes are important design parameters for structured surfaces, because of their relation with the surface support area. Table 1 shows the relation between Dimple Distance $\left(D_{\text {dimple }}\right)$ and the Apparent Support Area $\left(\mathrm{Ap}_{\mathrm{sa}}\right)$ besides the Dimple Density Index $\left(\mathrm{D}_{\mathrm{AD}}\right)$ used in the experimental investigation. A non-structured surface was used as a reference.

The dimples were manufactured with an usp (ultra-short pulse) Laser. The usp Laser removes the material by ablation, which is a very powerful technique for manufacturing surface structures. Laser ablation is a non-contacting wear-free technique and offers higher flexibility since the beam can be moved 
by very fast optical devices using mirrors and lenses. Furthermore, the laser apparatus including the radiation sources, control and movement devices, along with optical components, can be easily integrated into production environments. Hence, laser surface texturing became an increasingly relevant industrial manufacturing technique. While "Laser structuring" describes the general usage of pulsed laser ablation for forming structures, "Laser texturing" means the defined application of a desired surface topography on a work piece. The introduction of dimples on a surface can be classified and is better defined as a structuring process, since we are producing a 3D geometrically defined form with defined pattern on the surface [9, 20-23].

Pulsed laser ablation was used in this project for modifying the surfaces. The main characteristic of $u s p$ laser ablation is the thermal appearance of the material evaporation, which facilitates the manufacturing of surface microstructures with accurate geometries on a scale of several micrometers. The process is characterized according to the German standard DIN 8580 [14].

A Kern Evo (5-axis) Pikosekunden-Laserstrahl strukturier-system using a Laser source Lumera Super-Rapid $^{\odot}$, with $10 \mathrm{~W}$ average power at $500 \mathrm{kHz}$, $0-1,000 \mathrm{kHz}$ repetition rate, pulse on demand, ps-pulses with up to $200 \mu \mathrm{J}$ energy, $10 \mathrm{MW}$-range peak power, and high power stability in a high quality beam, $\mathrm{M}^{2}<1.3$ at all rep rates [24], were used to produce the structured dimples. The machining parameters for Tungsten carbide were $7 \mathrm{~W}$ power, $100 \mathrm{kHz}$ pulse frequency, $60 \mathrm{~mm} / \mathrm{s}$ speed and $1 / 0$ burst mode. For machining the dimples on an ANSI H13 disc, the parameters were $2.5 \mathrm{~W}$ power, $\mathrm{X} 100 \mathrm{kHz}$ pulse frequency, of $100 \mathrm{~mm} / \mathrm{s}$ speed.

\section{Experimental Analysis}

The pin-on-disc experiments were performed according to ASTM G99-95a [15]. The preparation and characterization of the pins and discs were accomplished by using the recommendations of ASTM G133-02 [16], since it was considered more complete.

A Wasau TRM 500 was used to perform pin-on-disc experiments. Before each experiment, a geometrical qualification of the test machine was performed to assure the perpendicularity and the parallelism between pin and disc contact surfaces. The experiments were performed by using a constant load force and progressive velocity. The tangential velocity steps are 0.016, 0.039, 0.078, 0.12, 0.16, 0.31, 0.47, 0.63, 0.79, 1.57 and $3.14 \mathrm{~m} / \mathrm{s}$, each velocity step was kept for $180 \mathrm{~s}$.

The pins were provided in two different materials: stainless steel ANSI 440C and Tungsten Carbide ISO P25. Table 2 shows the characterization of the pins.

The discs were manufactured in two materials: ANSI high speed steel H13 with a Young Modulus of $210 \mathrm{GPa}$ and hardness of $650 \pm 5 \mathrm{HV}$, its characteristics are shown in Table 3.

The loads were set to $10 \mathrm{~N}$ and $100 \mathrm{~N}$ for experiments performed with ANSI $440 \mathrm{C}$ pins against HSS H13 discs, and loads of $10 \mathrm{~N}$ and $30 \mathrm{~N}$ for Tungsten carbide ISO P25 pins against HSS H13 discs. The $100 \mathrm{~N}$ load provided an apparent load pressure $(\mathrm{Pa})$ of $384.6 \mathrm{~N} / \mathrm{mm}^{2}$ for $D_{\text {dimple }}=110 \mu \mathrm{m}, 120.5 \mathrm{~N} / \mathrm{mm}^{2}$ for $D_{\text {dimple }}=220 \mu \mathrm{m}$ and $106.4 \mathrm{~N} / \mathrm{mm}^{2}$ for $D_{\text {dimple }}=350 \mu \mathrm{m}$.

Table 2 Characterization of the pins.

\begin{tabular}{lll}
\hline Material & ANSI 440C & $\begin{array}{l}\text { Tungsten Carbide } \\
\text { ISO P25 }\end{array}$ \\
\hline $\begin{array}{l}\text { E [GPa] } \\
\text { Young Module } \\
\text { ratio (Epin/Edisc) }\end{array}$ & 200 & 620 \\
Hardness HV & 472 & $620 / 210=2.95$ \\
$\begin{array}{l}\text { Hardness ratio } \\
\text { (Pin/Disc) }\end{array}$ & $472 / 650=0.73$ & $1,510 / 650=2.32$ \\
$\mathrm{Sa}$ & $4,793,141 \mathrm{~nm}$ & $6,492,988 \mathrm{~nm}$ \\
$\mathrm{Sq}$ & $6,073,925 \mathrm{~nm}$ & $8,052,278 \mathrm{~nm}$ \\
$\mathrm{Sz}$ & $80,018 \mu \mathrm{m}$ & $52,645 \mu \mathrm{m}$ \\
\hline
\end{tabular}

Table 3 Characterization of the discs.

\begin{tabular}{llll}
\hline $\mathrm{Sa}$ & $0.2052 \mu \mathrm{m}$ & $\mathrm{Sz}$ & $6.833 \mu \mathrm{m}$ \\
$\mathrm{Sq}$ & $0.2706 \mu \mathrm{m}$ & $\mathrm{Ssk}$ & -1.065 \\
$\mathrm{Sp}$ & $4.358 \mu \mathrm{m}$ & $\mathrm{Sku}$ & 5.689 \\
$\mathrm{~Sv}$ & $2.475 \mu \mathrm{m}$ & $\mathrm{Smr}$ & $2.133 \mathrm{e}-005 \%$ \\
$\mathrm{Spx}$ & $0.6748 \mu \mathrm{m}$ & $\mathrm{Smc}$ & $0.2999 \mu \mathrm{m}$ \\
\hline
\end{tabular}


The $10 \mathrm{~N}$ load provided an apparent load pressure of $10 \mathrm{~N} / \mathrm{mm}^{2}, 38.5 \mathrm{~N} / \mathrm{mm}^{2}$ for $D_{\text {dimple }}=110 \mu \mathrm{m}$, $12.1 \mathrm{~N} / \mathrm{mm}^{2}$ for $D_{\text {dimple }}=220 \mu \mathrm{m}$ and $10.6 \mathrm{~N} / \mathrm{mm}^{2}$ for $\mathrm{D}_{\text {dimple }}=350 \mu \mathrm{m}$.

Five repetitions were performed for each experiment; for those with high dispersion in the results, three other experiments were set, with the worst result being discarded/disregarded. The data acquisition rate was 1 $\mathrm{kHz}$ and a low pass filter with $25 \mathrm{~Hz}$ cutting frequency was set. The lubrication used an emulsion of a mineral oil-based semi-synthetic Blaser B-Cool 9665 [17] in water, with a concentration of $10 \%$.

\section{Experimental Results}

The results from pin-on-disc experiments working with lubrication under progressive speed and constant load for the ANSI 440C pin against a HSS H13 disc are shown in Fig. 2.

Fig. 3 presents the same comparative analysis for dimple-textured surfaces against a non-textured surface. The experiments were performed under lubrication,

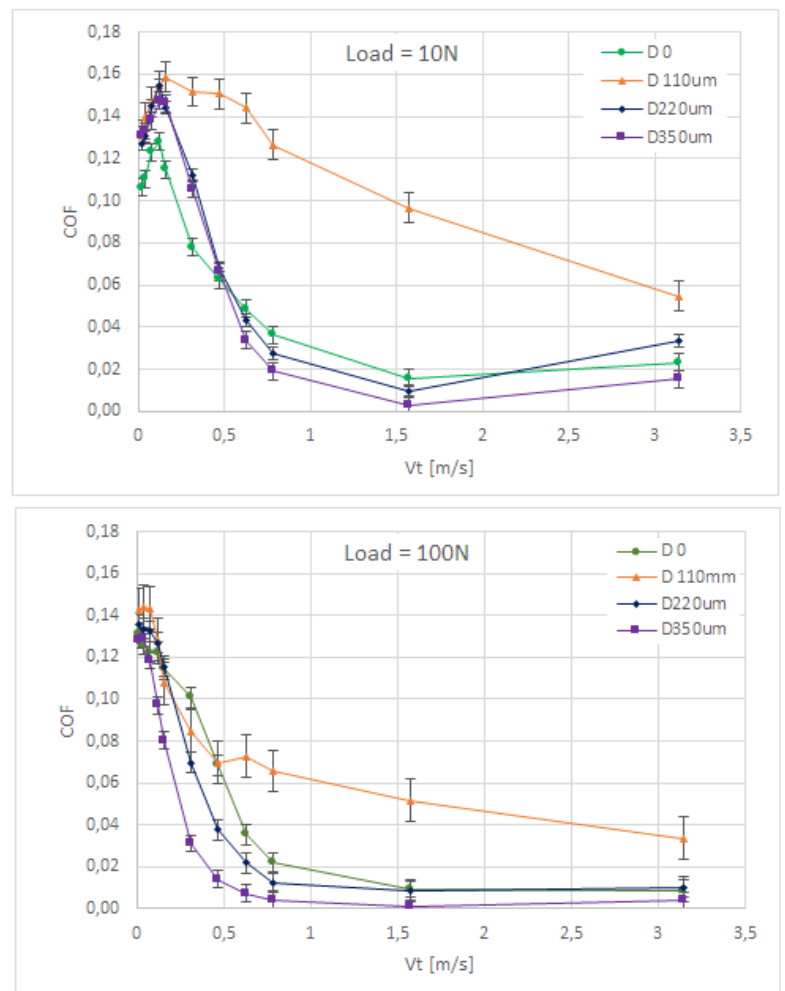

Fig. 2 Coefficient of Friction for progressive speed for an ANSI 440C pin against a HSS ANSI H13 disc.
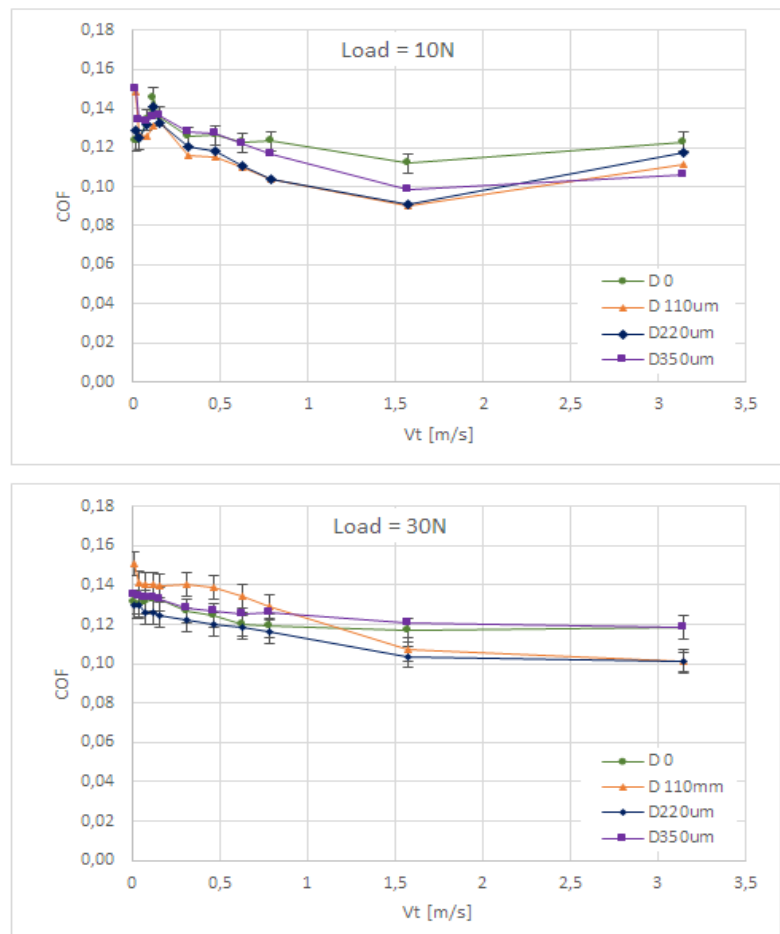

Fig. 3 Coefficient of Friction for a progressive speed, Tungsten Carbide ISO P25 against a HSS ANSI H13 disc.

progressive speed and constant load, for a Tungsten Carbide ISO P25 pin against a HSS H13 disc.

\section{Numerical Simulation}

The numerical simulation was performed by using the VTL (Virtual Tribology Lab) [16, 17]. The VTL is a free access software designed for reciprocating test simulation. It can simulate the contact problem for textured surfaces or not, operating with or without lubrication. The VTL has three main simulation options:

(a) Instantaneous: which shows the instantaneous condition in terms of asperities contact pressure and hydrodynamic pressure at the interface of body and counter-body;

(b) Reciprocating mode, which simulates the full movement of the test and shows the hydrodynamic pressure and friction coefficient;

(c) Wear mode, which predicts the amount of wear and the final roughness of the surface.

In order to understand the contact problem in a pin-on-disc experiment using dimple-structured surfaces, 
only the Instantaneous mode was used for the simulations. The program allows selecting two contact models: The Greenwood Williamson and the Greenwood-Tabor. The Greenwood Williamson is recommended for the contact problem of rough surfaces and the Greenwood-Tabor model is recommended for fine roughness surfaces. Fig. 4 shows a general view of the instantaneous simulation at two different instants of the pin displacement.

Instantaneous mode: (a) the velocity was set as constant and equivalent to the tangential velocity in the pin-on-disc test, there is no velocity profile as in the reciprocate test; (b) the linear displacement for the reciprocating were equivalent to $n$ turns of the disc for a pin-and-disc experiment. The translation in a half cycle of the reciprocating displacement was set as equivalent to the perimeter for one turn at the pin-on-disc test, considering the radius from the disc to the pin center.

The 3D surfaces parameters used in the simulations came from Tables 2 and 3. Fig. 5 presents a general view for the instantaneous mode simulation form progressive speeds for an ANSI 440C pin against a HSS H13 disc, at a constant load of $100 \mathrm{~N}$.
A comparative analysis between numercial and experimental coeficient of friction for a steel ANSI 440C pin against a HSS ANSI H13 disc is shown in Figs. 6-8.

The simulations of all the other experimental conditions show the same tendency, with a predominance of hydrodynamic pressure at higher speed; this condition was expected. In some cases, a full hydrodynamic lubrication condition, with full separation of the surfaces, was observed in the simulations, which shows a discrepancy regarding the experiments, in which this condition was not observed.

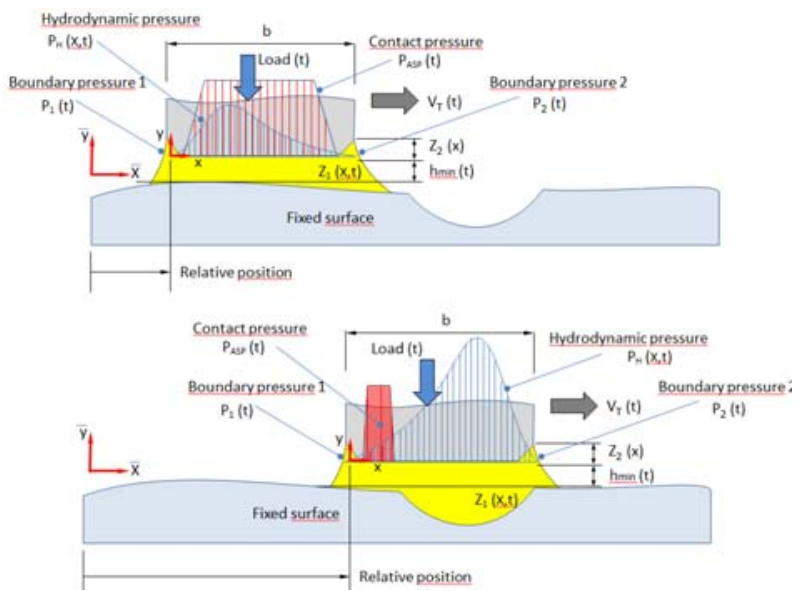

Fig. 4 View of the instantaneous simulation.
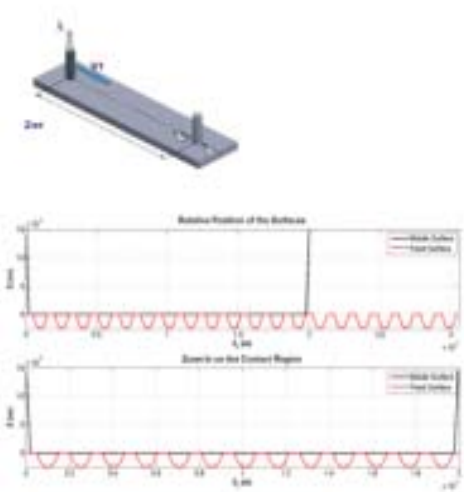

Pin ANSI 440C

Pin diamedar. $2 \mathrm{~mm}$

DisC: HSS H13

Dimples: Soheric $100 \times 25$ unt

Ddimple 110 um

Lubricante. Emution $10 \%$

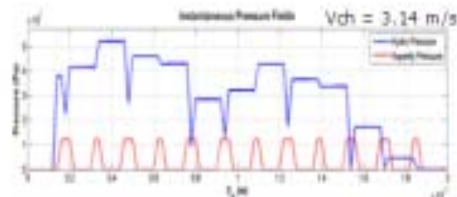

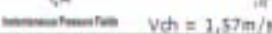
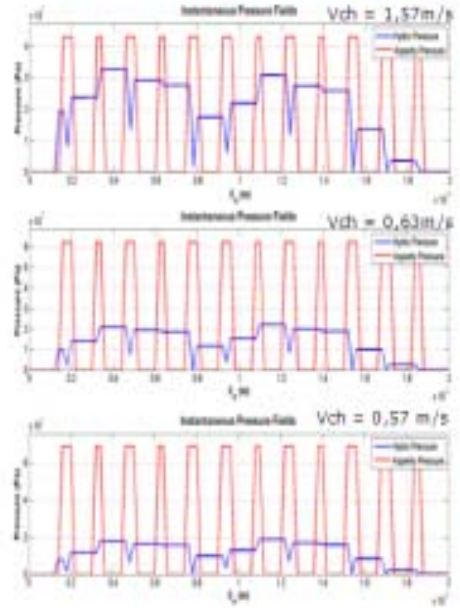
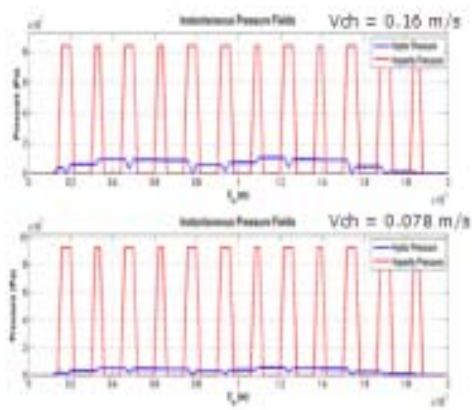

val $=0.039 \mathrm{~m} / \mathrm{s}$
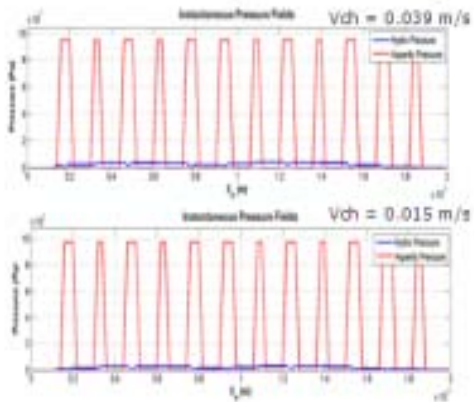

Fig. 5 General view of the instantaneous mode simulation form progressive speeds for an ANSI 440C pin against a HSS H13 disc, at a constant load of $100 \mathrm{~N}$. 

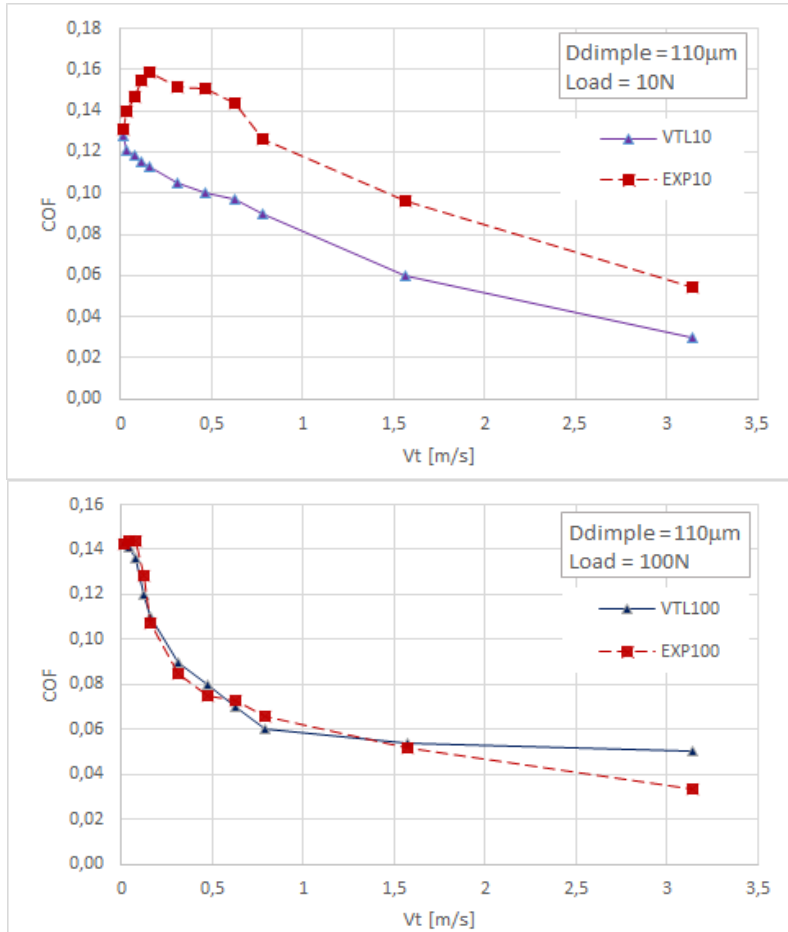

Fig. 6 Comparative analysis between numercial and experimental coeficient of friction for steel ANSI 440C pin against HSS ANSI $\mathrm{H13}$ disc, with a low density of dimples $\left(D_{\text {dimple }}=110 \mu \mathrm{m}\right)$.
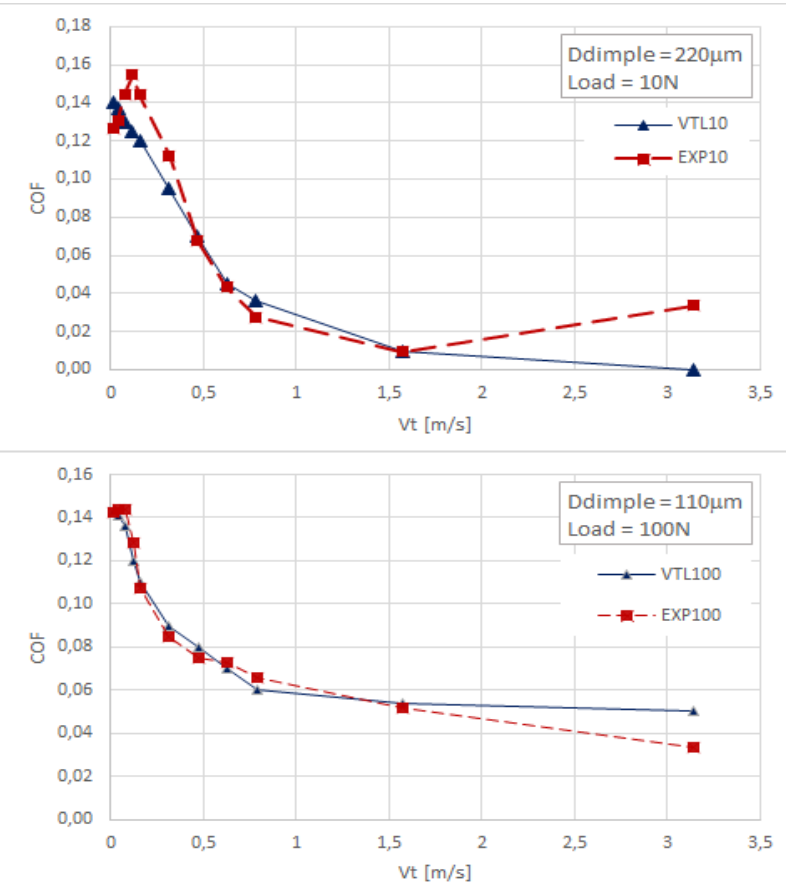

Fig. 7 Comparative analysis between numerical and experimental coeficient of friction for steel ANSI 440C pin against HSS ANSI H13 disc, with a medium density of dimples $\left(D_{\text {dimple }}=220 \mu \mathrm{m}\right)$.
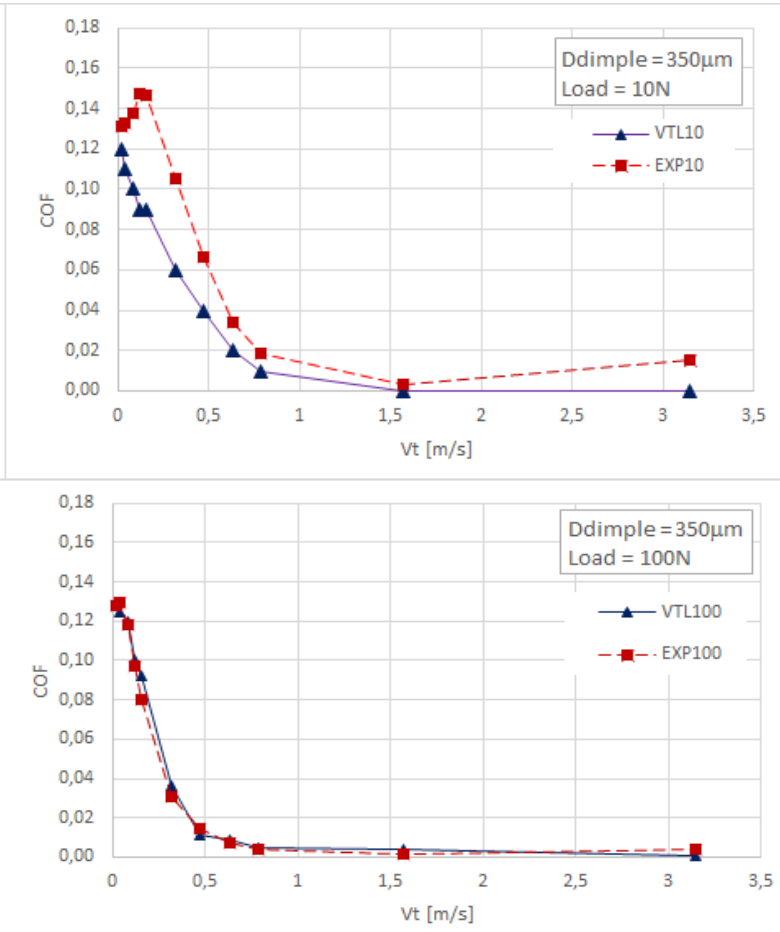

Fig. 8 Comparative analysis between numerical and experimental coeficient of friction for a steel ANSI $440 \mathrm{C}$ pin against a HSS ANSI H13 disc, with a high density of dimples $\left(D_{\text {dimple }}=350 \mu \mathrm{m}\right)$.

\section{Conclusions}

Based on the results, it is possible to suggest that the design of dimple-structured surfaces rely on nine main parameters:

- material of contact pair;

- hardness of the materials under contact;

- Young Modulus of the materials under contact;

- roughness of the surfaces under contact;

- dimple design: shape, dimensions, orientation regarding the movement direction;

- dimple distribution;

- applied load;

- velocity between the body in contact;

- lubricant type: viscosity and temperature.

A better performance can be obtained from a compromise solution over these parameters, and the dimple concentration prevails over the other parameters. The best results were those with a lower concentration of dimples, under higher speed and load. 
The pair of material ANSI 440C / HSS ANSI H13 with a hardness ratio 0.73 shows that a high concentration of dimples brings no improvement over the friction, and the loss of support area led to an increase of the load over the asperities, resulting in a higher COF. The experiments with this pair also showed a transition point at the speed of $0.47 \mathrm{~m} / \mathrm{s}$, at which the additional lift force produced by dimples can be observed. This transition is in conformity with the hydrodynamic theory, and the graphs show accordance with the Stribeck curve, except for the results for high concentration of dimples $\left(D_{\text {dimple }}\right.$ $110 \mu \mathrm{m})$. At high speed, the gains obtained with dimples are not significant independently of the load. This leads to the conclusion that dimple-structured surfaces have an optimum area of operation, in relations of speed.

During the experiments the pair Tungsten Carbide ISO P25/HSS under a $10 \mathrm{~N}$ load, at all speeds tested produces a lower Coefficient of Friction. For a load of $30 \mathrm{~N}$ a D220 $\mu \mathrm{m}$, there is a reduction of COF at all speeds. A transition over the COF at higher speed is also observed for a high concentration of dimples (D110 $\mu \mathrm{m}$ ), and no gain for a low concentration (D350 $\mu \mathrm{m})$ of dimples at all speeds.

A better performance can be achieved from a compromise solution over these parameters. There is an optimum relation between tangential speeds, load and dimple concentration that should be explored. The dimple concentration prevails over the other parameters, with no significant gain with low-density dimple distribution.

The simulation allows observing the evolution of the asperities contact pressure and the hydrodynamic pressure acts at the interface. This provides guidelines for designing dimple-structured surfaces. Dimple-structured surfaces can perform well once correctly designed, manufactured and operated at optimum conditions, with the right pair of materials. Structured surfaces performance should be improved with the addition of thin films layers; also, the performance should be investigated under minimum lubrication conditions.

\section{Acknowledgment}

The authors would like to thanks the Brazilian Coordination for the Improvement of Higher Education Personnel (CAPES) and the Deutsche Forschungsgemeinschaft (DFG Germany), and the Brazil Germany program of advanced manufacturing (Bragecrim) for supporting this research.

\section{References}

[1] Hamilton, D. B., Walowit, J. A., and Allen. C. M. 1969. "A Theory of Lubrication by Microirregularities." $J$. Fluids Eng. 88 (1): 177-85. doi:10.1115/1.3645799.

[2] Moore, W. R. 1970. Foundations of Mechanical Accuracy. USA: Moore Special Tool Co.

[3] Profito, F. J., Zachariadis, D. C., and Tomanik, E. 2011. "One-Dimensional Mixed Lubrication Regime Model for Textured Piston Rings." Presented at the 21st Brazilian Congress of Mechanical Engineering, Natal, RN, Brazil.

[4] Etsion, I., Halperin, G., Brizmer, V., and Kligerman, Y. 2004. "Experimental Investigation of Laser Surface Textured Parallel Thrust Bearings." Tribology Letters 17 (2): 295-300

[5] Etsion, I., Kligerman, Y., and Ronen, A. 2001. "Friction-Reducing Surface-Texturing in Reciprocating Automotive Components." Tribology Transactions 44 (3): 359-66.

[6] Etsion, I., Kligerman, Y., and Halperin, G. 1999. "Analytical and Experimental Investigation of Laser-Textured Mechanical Seal Faces." Tribology Transactions 42 (3): 511-6.

[7] Yagi, K., Takedomi, W., Tanaka, H., and Sugimura, J. 2008. Improvement of Lubrication Performance by Micro Pit Surfaces, Tribology Online, Tribology Conference.

[8] Hoppermann, A., and Kordt, M. 2004. "Laser Structured Contact Surfaces-Effects on the Tribological Behaviour of Hydraulic Material Combinations." O + P Ölhydraulik und Pneumatik 48 (10): 1-13.

[9] Kovalchenko, A., Ajayi, O., Erdemir, A., Fenske, G., and Etsion, I. 2005. "The Effect of Laser Surface Texturing on Transition in Lubrication Regimes during Unidirectional Sliding Contact.” Tribology International 38: 219-25.

[10] Wang, X., Liu, W., Zhou, F., and Zhu, D. 2009. "Preliminary Investigation of the Effect of Dimple Size on Fricition in Line Contacts." Tribology International 42: 1118-23.

[11] Shinkaremko, A., Kligermann, Y., and Etsion, I. 2009. 
"The Effect of Surface Texturing in Soft Elasto-Hydrodynamic Lubrication." Tribology International 42 (2): 284-92.

[12] Siegel, F., Klug, U., and Kling, R. 2009. "Extensive Micro-Structuring of Metals Using Picosecond Pulses-Ablation Behavior and Industrial Relevance." Journal of Laser Micro/Nanoengineering 4 (2): 104-10.

[13] Brinksmeier, E., Gläbe, R., and Flucke, C. 2007. "Manufacturing of Molds for the Replication of Prismatic Microstructures by a Novel Diamond Cutting Process." Industrial Diamond Review 1/07: 25-30.

[14] DIN 8580. Manufacturing Processes-Terms and Definitions. Division. 2003-09.

[15] ASTM G99-05. 2010. Standard Test Method for Wear Testing with a Pin-on-Disk Apparatus.

[16] ASTM G133-02. Standard Test Method for Linearly Reciprocating Ball-on-Flat Sliding Wear.

[17] Blaser Material Safety Data Sheet. 2014. in: http://www.cuttingfluids.com.mx/es/wp-content/uploads/ 2014/09/B-Cool_9665.pdf, acess in 06.2014.

[18] Virtual Tribology Lab Tutorial (VTL 3.8). 2014.
http://www.lfs.usp.br/Portal_Triboflex/Mahle/VTL. Acessed in 07.2014.

[19] Profito, F. 2010. "Modelagem Unidimensional do Regime Misto de Lubrificação Aplicada a Superfícies Texturizadas." M.Sc. dissertation, University of São Paulo.

[20] Dunn. A., Carstensen. J. V., Wlodarczyk, K. L., Hansen, E. B., Gabzdyl, J., Harrison, P. M., Shephard, J. D., and Hand, D. P. 2014. "Nanosecond Laser Texturing for High Friction Applications." Optics and Lasers in Engineering 62: 9-16.

[21] Poprawe, R. 2004. Lasertechnik für die Fertigung. Springer.

[22] Cichkov, B. N., Momma, C., Nolte, S., Von Alvensleben, F., and Tuennermann, A. 1996. "Femtosecond. picosecond and nanosecond laser ablation of solids." Appl. Phys. A 63: 109-15.

[23] Nolte, S., Momma, C., Jacobs, H., Tünnermann, A., Chichkov, B. N., Wellegehausen, B., and Welling, H. 1997. "Ablation of Metals by Ultrashort Laser Pulses." J. Opt. Soc. Am. B 14 (10): 2716-22. 